\title{
METODE IMPROVED CHAID (CHI-SQUARED AUTOMATIC INTERACTION DETECTION) PADA ANALISIS KREDIT MACET BMT (BAITUL MAL WA TAMWIL)
}

\author{
Muhammad Muhajir \\ Program Studi Statistika FMIPA Universitas Islam Indonesia \\ Jalan Kaliurang KM 14,5, Sleman, Yogyakarta, 55584 \\ E-mail: muhammad.muhajir.stat89@gmail.com
}

\begin{abstract}
ABSTRAK
Penelitian ini bertujuan untuk menetukan segmentasi nasabah berdasarkan karakteristik status kreditnya pada BMT El Bummi 372. Segmentasi ini bertujuan untuk mengidentifikasi segmen nasabah potensial dengan harapan resiko kredit macet yang dapat diminimumkan. Penelitian ini menggunakan data sekunder, yang terdiri dari 945 nasabah yang terdiri dari 94 macet dan 851 tidak macet. Salah satu metode riset segmentasi yaitu Improved CHAID (Chi-Squared Automatic Interaction Detection analysis) yang merupakan perbaikan dari metode $C H A I D$ dengan mengelaborasi tabel kontingensinya dengan Tschuprow's T. Improved CHAID akan menghasilkan diagram yang mirip dengan diagram pohon keputusan yang menyediakan informasi tentang derajat hubungan antara variabel dependen terhadap variabel independen serta informasi mengenasi karakteristik segmen. Pada kasus BMT El Bummi 372,didapatkan enam segmen. Segmen nasabah dengan karakteristik pendidikan (Diploma/S1/Profesi, S2/S3), usia $\leq 50$ tahun, ukuran keluarga $\leq 3$ orang dan penghasilan $>$ Rp. $1.500 .000,00$ adalah segmen yang memiliki rasio kredit macet yang paling rendah.
\end{abstract}

Kata Kunci: Segmentasi nasabah, Status Kredit, Tschuprow's T, Improved CHAID

\section{ABSTRACT}

This research aims to determine customer segmentation based on characteristics of credit status customers in BMT EL Bummi 372. The aim of this segmentation to identify a potential customer by loan status stalledwhich can be minimized. This research used secondary data, which consist of 94 customers withunpaid status and 851 customers withpaid status. One of method market segmentation is Improved CHAID (Chi-Squared Automatic Interaction Detection analysis) which improved contingency table by Tschuprow's T. Improved CHAID will produce the decision tree which provide information on degrees relations between variables dependent on variables independent and information about characteristic segments. In BMT El Bummi 372 case, there are six segments were identified. Relationship segment which haseducation (elementary school, junior high school, and senior high school), less than equal 50 years, family size less than equal 3 persons, and monthly income more than Rp 1.500.000,00 is the lowest ratio of unpaid credit segment.

Keyword: Customer segmentation, Credit status, Tschuprow's T, Improved CHAID

\section{Pendahuluan}

Globalisasi di Indonesia, sektor perusahaan jasa seperti Baitul Mal Wa Tamwil (BMT). Persaingan antar

menyebabkan tingginya kompetisi pada BMT yang semakin ketat untuk menarik Metode Improved CHAID (chi-squared automatic interaction detection) Pada Analisis Kredit Macet BMT (Baitul Mal wa Tamwil)

Muhammad Muhajir 
minat para konsumen atau mempertahankan nasabah dalam roda bisnis perekonomian merupakan salah satu cara dalam mempertahankan eksitensinya.

Setiap perusahaan jasa khususnya BMT, selalu berusaha untuk mencapai target dengan cara menarik nasabah sebanyak-banyaknya untuk menabung maupun pemberian pembiayaan (kredit) di BMT tersebut (Suhendi dkk, 2004). Pembiayaan yang diberikan kepada para nasabah tidak akan lepas dari resiko terjadinya pembiayaan bermasalah yang akhirnya dapat memengaruhi terhadap kinerja bank syariah ataupun lembaga keuangan syariah lainnya tersebut (Samti, 2011).

Dalam rangka meminimalkan resiko kredit tersebut, dapat dilakukan dengan cara memperhatikan faktor ketidaklayakan debitur melalui status demografi nasabahnya berdasarkan status kredit, sehingga diperlukan segmentasi pasar berdasarkan hubungan faktor-faktor tersebut (Kunto dan Hasana, 2006).

Dari beberapa metode segmentasi pasar (nasabah) yang ada, penulis tertarik menggunakan metode Improved CHAID (Chi-Squared Automatic Interaction Detection). Metode ini dipilih karena menghasilkan improvisasi tabel kontingensi Tschuprow's $T$ pada algoritma CHAID, sehingga hasil segmentasinya akan lebih baik. Metode ini digunakan pada segmentasi nasabah, dan diharapkan dapat menemukan aturan klasifikasi yang dapat digunakan untuk memprediksi potensi seorang nasabah baru dengan pinjaman berstatus macet.

\section{Tujuan Penelitian}

Penelitian ini bertujuan untuk mengidentifikasi segmen nasabah potensial dengan harapan resiko kredit macet dapat diminimumkan berdasarkan aturan klasifikasi yang sesuai.

\section{Metode Penelitian}

Untuk melakukan segmentasi nasabah yang potensial dengan cara mengimplementasikannya dengan metode klasifikasi pohon Improve CHAID. Sistem tersebut memiliki tiga buah komponen utama yaitu :

i. Variabel dataset nasabah BMT El Bummi 372 (input)

ii. Proses signifikansi variabel dengan uji Tschuprow's T untuk pembentukan segmen nasabah

iii. Proses pembuatan diagram pohon Improve CHAID dengan aturan "Top-down stopping rule"

Data dan software yang digunakan dalam penelitian ini adalah

Metode Improved CHAID (chi-squared automatic interaction detection) Pada Analisis Kredit Macet BMT (Baitul Mal wa Tamwil) 
data sekunder, yaitu data Pengguna Pembiayaan BMT El Bummi 372 Patuk, Gunung Kidul tahun 2011-2013 yang akan diolah pada software SIPINA. Data yang diambil hanyalah data nasabah yang melakukan peminjaman selama tahun 2011-2013. Data tersebut kemudian dipergunakan sebagai variabel dalam melakukan analisis Improved CHAID. Variabel dalam penelitian ini terdiri dari variabel dependen dan independen sebagai berikut (Kunto dan Hasana, 2006):

\section{a) Variabel Dependen}

Variabel dependen yang digunakan dalam penelitian ini adalah pengguna pembiayaan BMT yang dibedakan menjadi dua kategori, yaitu:

1. Nasabah dengan pinjaman yang berstatus macet (M)

2. Nasabah dengan pinjaman yang berstatus tidak macet (TM)

\section{b) Variabel Independen}

Variabel independen dalam
penelitian ini diambil dari
variabel demografis data
pengguna pembiayaan BMT.
Variabel tersebut terdiri dari lima
komponen demografis, yaitu:

1. Usia
Usia nasabah dibedakan sebagai berikut:

- Usia Remaja ( $\leq 23$ tahun)

Usia remaja merupakan usia transisi yang pada umumnya sangat mudah dipengaruhi oleh faktor-faktor eksternal.

- Usia 24 - 30 tahun

Usia ini merupakan usia kedewasaan nasabah serta biasanya usia di mana nasabah mulai merintis karir dalam kehidupannya.

- Usia 31 - 40 tahun

Usia yang merupakan usia peningkatan karir dan kematangan dalam bersikap.

- Usia 41 - 50 tahun

Usia di mana pada masa ini biasanya menjadi masamasa kejayaan bagi nasabah dan masa di mana kemapanan diraih.

- Usia Lanjut ( $\geq 51$ tahun)

Usia di mana nasabah mulai menikmati hari tuanya.

2. Pendidikan terakhir

Nasabah dapat dikelompokkan menurut tingkat pendidikan yang telah dicapai. Dalam hal ini tingkat

Metode Improved CHAID (chi-squared automatic interaction detection) Pada Analisis Kredit Macet BMT (Baitul Mal wa Tamwil) 
pendidikan nasabah akan dibagi menjadi:

- SD

- SMP/sederajat

- SMU/sederajat

- Diploma/S1/Profesi

- S2/S3

3. Penghasilan rata-rata keluarga Penghasilan rata-rata keluarga nasabah per bulan BMT ini dibagi menjadi:

- $\leq$ Rp. 750.000,00

- Rp. 750.000,00 - Rp. $1.500 .000,00$

- Rp. 1.500.000,00 - Rp. $2.000 .000,00$

- $\geq$ Rp. $2.000 .000,00$

4. Ukuran keluarga

Ukuran keluarga adalah jumlah orang atau individu dalam satu rumah tempat nasabah tinggal. Variabel ini dibedakan atas:

- 1 orang

- 2 orang

- 3 orang

- 4 orang

- 5 orang atau lebih

\section{RancanganPenelitian}

\section{Algoritma Improved CHAID}

Secara umum ada dua tahap utama dalam algoritmaImproved CHAID sebagai berikut (Belaid, 2001):
1) Memisahkan dataset menjadi training dan testing data

Pada tahap ini dataset dibagi menjadi dua antara lain training data yaitu data yang akan dijadikan input dalam proses pembentukkan pohon klasifikasi untuk menemukan aturan klasifikasi. Testing data yaitu data yang akan digunakan dalam pengujian aturan klasifikasi yang telah terbentuk.

\section{2) Melakukan Proses Analisis CHAID}

Ada lima langkah analisis $C H A I D$ dengan Tschuprow's $T$ sebagai berikut (Kass, 1980):

Untuk tiap variabel independen, $X_{1}$, $X_{2}, \ldots X_{k}$ dan variabel dependen $Y$

1. Bentuk tabel kontingensi dua arah dengan variabel dependennya berdasarkan Tschuprow's $T$.

2. Hitung statistik Tschuprow's T untuk setiap pasang kategori yang dapat dipilih untuk digabung menjadi satu, untuk menguji kebebasannya dalam sebuah sub tabel kontingensi 2 x 2 atau minimal dua kelompok yang menunjukkan bahwa jumlah kelompok adalah persis sama dengan jumlah nilai kelas.

3. Hitung p-value terkoreksi Bonferroni didasarkan pada tabel

Metode Improved CHAID (chi-squared automatic interaction detection) Pada Analisis Kredit Macet BMT (Baitul Mal wa Tamwil) 
yang telah digabung(Sharp dkk, 2002).

4. Pilihlah variabel independen terbaik, yaitu variabel independen dengan nilai p-value yang terendah, dan kemudian melakukan pembagian kelompok dengan variabel independen ini (yaitu gunakan masing-masing kategori-kategori variabel independen tersebut, yang telah digabung secara optimal, untuk menentukan sub pembagian dari kelompok induk menjadi sub kelompok yang baru). Jika tidak ada variabel independen dengan nilai $p$-value yang signifikan, jangan memulai pembagian kelompok tersebut.

5. Kembali ke langkah nomor 1 untuk menganalisis sub kelompok berikutnya. Hentikan ketika semua sub kelompok telah dianalisis dan juga telah berisi pengamatan-pengamatan dengan jumlah yang terlalu sedikit.

6. Lihat tingkat akurasi dari aturan yang telah terbentuk dari hasil pohon klasifikasi. Klasifikasi dengan tingkat keakuratan $\geq 80 \%$ yang dianjurkan (baik) digunakan dalam pengklasifian (Ramdhany dkk, 2006).
Alur kerja segmentasi nasabah dengan metode Improved CHAID digambarkan pada Gambar 1.

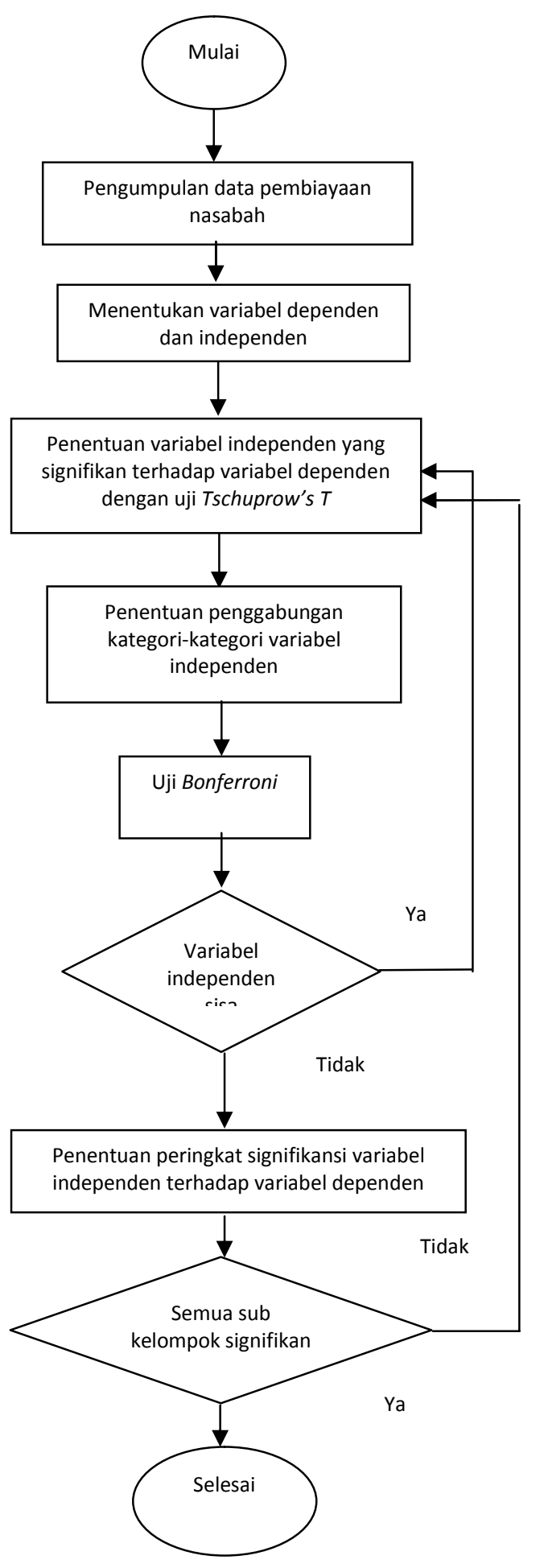

Gambar 1. Rancangan Penelitian

Metode Improved CHAID (chi-squared automatic interaction detection) Pada Analisis Kredit Macet BMT (Baitul Mal wa Tamwil) 


\section{Pembahasan}

Pada bab ini akan dibahas aplikasi algoritma Improved CHAID dalam penentuan segmentasi nasabah yang mempunyai dataset berskala ordinal. Metode ini digunakan pada segmentasi nasabah, dan diharapkan dapat menemukan aturan klasifikasi yang dapat digunakan untuk memprediksi potensi seorang nasabah baru dengan pinjaman berstatus macet

\section{Demografi Nasabah}

Data yang diambil hanyalah data nasabah yang melakukan peminjaman selama tahun 2011-2013. Jumlah total nasabah pada kurun waktu tiga tahun tersebut adalah sebanyak 945 nasabah. Data tersebut kemudian dipergunakan sebagai variabel dalam melakukan analisis Improved CHAID. Deskripsi data peminjam BMT El Bummi 372 yang melakukan peminjaman dapat dilihat pada Tabel 1.

Berdasar Tabel 1 terlihat, bahwa nasabah peminjam kredit terbanyak berdasarkan variabelnya yaitu usia antara 41-50 tahun sebanyak 359 orang, pendidikan terakhir SMP/Sederajat sebanyak 308 orang, penghasilan antara Rp. 750.000,00 - Rp. 1.500.000,00, dan ukuran keluarga 2 orang sebanyak 340 orang.
Tabel 1. Deskriptif Data

\begin{tabular}{|c|c|c|}
\hline Variabel Dependen & Frekuensi & $\begin{array}{l}\text { Prosentase } \\
\text { (\%) }\end{array}$ \\
\hline $\begin{array}{l}\text { Status Kredit } \\
\text { 1. } \quad \text { Macet } \\
\text { 2. } \\
\text { Tidak macet }\end{array}$ & $\begin{array}{c}94 \\
851\end{array}$ & $\begin{array}{r}9.95 \\
90.05\end{array}$ \\
\hline Variabel Independen & & \\
\hline $\begin{array}{l}\text { Usia } \\
\text { 1. Usia Remaja ( } \leq 23 \text { tahun) } \\
\text { 2. Usia } 24-30 \text { tahun } \\
\text { 3. Usia } 31-40 \text { tahun } \\
\text { 4. Usia } 41-50 \text { tahun } \\
\text { 5. Usia Lanjut ( } \geq 51 \text { tahun) }\end{array}$ & $\begin{array}{c}43 \\
129 \\
269 \\
359 \\
145\end{array}$ & $\begin{array}{c}4.55 \\
13.65 \\
28.47 \\
37.99 \\
15.34\end{array}$ \\
\hline 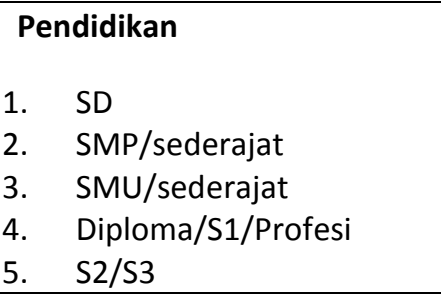 & $\begin{array}{c}161 \\
308 \\
282 \\
167 \\
27\end{array}$ & $\begin{array}{c}17.04 \\
32.59 \\
29.84 \\
17.67 \\
2.86\end{array}$ \\
\hline $\begin{array}{l}\text { Penghasilan } \\
\begin{array}{ll}1 . \quad \leq \text { Rp. } 750.000,00 \\
\text { 2. } & \text { Rp. } 750.000,00-\text { Rp. } \\
& 1.500 .000,00 \\
\text { 3. } & \text { Rp. } 1.500 \cdot 000,00-\text { Rp. } \\
& \text { 2.000.000,00 } \\
\text { 4. } \quad \text { Rp. } 2.000 .000,00\end{array}\end{array}$ & $\begin{array}{r}342 \\
296 \\
199 \\
108\end{array}$ & $\begin{array}{r}36.19 \\
31.32 \\
\\
21.06 \\
\\
11.43\end{array}$ \\
\hline $\begin{array}{l}\text { Ukuran Keluarga } \\
\begin{array}{l}\text { 1. } \\
\text { 2 Orang } \\
\text { 2. } 2 \text { Orang } \\
\text { 3. } 3 \text { Orang } \\
\text { 4. } 4 \text { Orang } \\
\text { 5. } 5 \text { Orang atau lebih }\end{array}\end{array}$ & $\begin{array}{c}52 \\
340 \\
185 \\
183 \\
185\end{array}$ & $\begin{array}{c}5.50 \\
35.98 \\
19.58 \\
19.37 \\
19.58\end{array}$ \\
\hline
\end{tabular}




\section{Aplikasi Algoritma Improved CHAID}

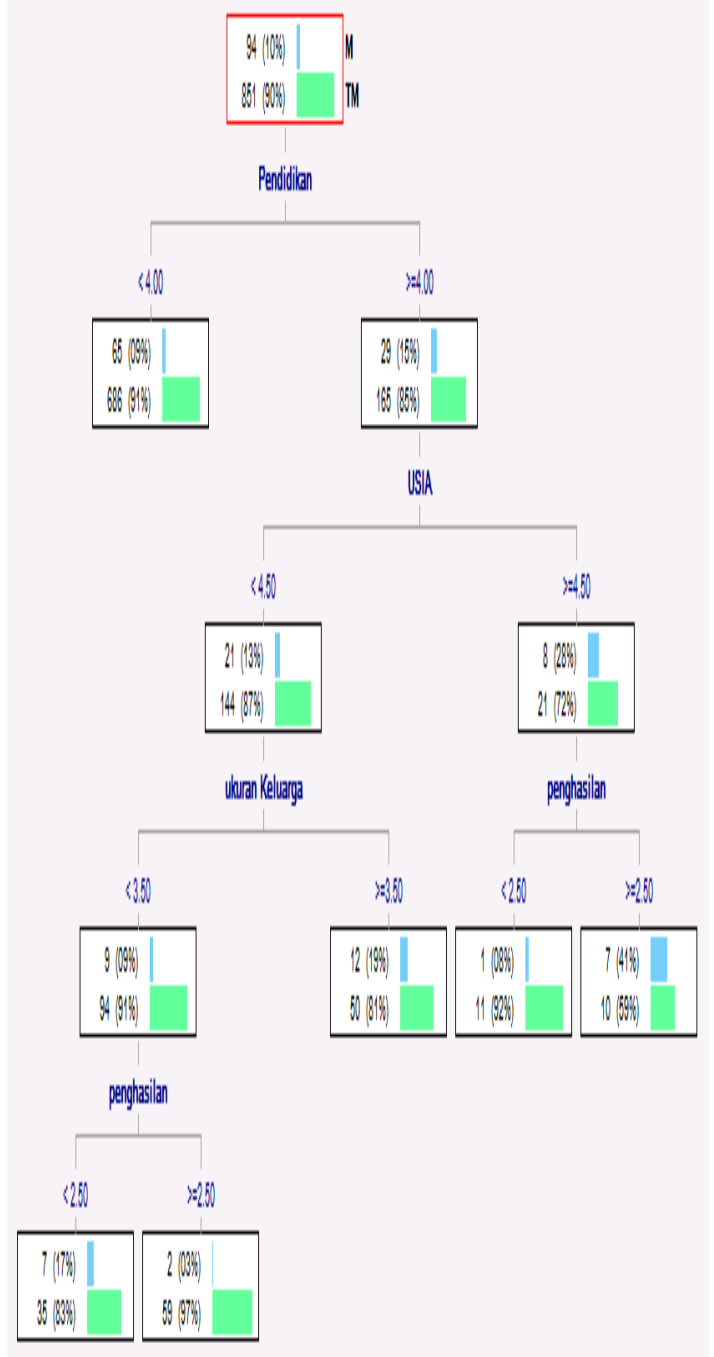

Gambar 2. Hasil Pohon Klasifikasi Improved CHAID

Dari pohon analisis Improved CHAID pada Gambar 2 diketahui bahwa pada node teratas diketahui jumlah total nasabah 945 nasabah, terdiri dari 94 nasabah (10\%) dengan status kreditnya macet dan 851 nasabah (90\%) dengan status kredit yang tidak macet. Dari pohon klasifikasi Improved CHAID terbentuk enam segmen yang berbeda, sebagai berikut:

1. Jika nasabah dengan pendidikan $<4$ (SD, SMP, SMA), maka dari data diperoleh Tidak Macet sebanyak 686 nasabah dan Macetsebanyak 65 nasabah. Sehingga nasabah pada kelompok ini diduga akan mengalami kemacetan.

2. Jika nasabah dengan pendidikan $\geq 4$ (Diploma/S1/Profesi, S2/S3), usia < 4.5 ( $\leq 50$ tahun), ukuran keluarga $<$ 3.5 ( $\leq 3$ orang) dan penghasilan $<2.5$ ( $\leq$ Rp. 1.500.000,00), maka dari data diperoleh Tidak Macet sebanyak 35 nasabah dan Macet sebanyak 7 nasabah. Sehingga nasabah pada kelompok ini diduga akan mengalami kemacetan.

3. Jika nasabah dengan pendidikan $\geq 4$ (Diploma/S1/Profesi, S2/S3), usia < 4.5 ( $\leq 50$ tahun), ukuran keluarga $<$ 3.5 ( $\leq 3$ orang) dan penghasilan $\geq 2.5$ (>Rp. 1.500.000,00), maka dari data diperoleh Tidak Macet sebanyak 59 nasabah dan Macet sebanyak 2 nasabah. Sehingga nasabah pada kelompok ini diduga tidak akan mengalami kemacetan.

4. Jika nasabah dengan pendidikan $\geq 4$ (Diploma/S1/Profesi, S2/S3), usia < 4.5 ( $\leq 50$ tahun) dan ukuran keluarga $\geq$ 3.5 ( $\geq 4$ orang), maka dari data diperoleh Tidak Macet sebanyak 50

Metode Improved CHAID (chi-squared automatic interaction detection) Pada Analisis Kredit Macet BMT (Baitul Mal wa Tamwil) 
nasabah dan Macet sebanyak 12 nasabah. Sehingga nasabah pada kelompok ini diduga akan mengalami kemacetan.

5. Jika nasabah dengan pendidikan $\geq 4$ (Diploma/S1/Profesi, S2/S3), usia $\geq$ 4.5 ( $\geq 51$ tahun) dan penghasilan $\geq 2.5$ (>Rp. 1.500.000,00), maka dari data diperoleh Tidak Macet sebanyak 11 nasabah dan Macet sebanyak 1 nasabah. Sehingga nasabah pada kelompok ini diduga akan mengalami kemacetan.

6. Jika nasabah dengan pendidikan $\geq 4$ (Diploma/S1/Profesi, S2/S3), usia $\geq$ 4.5 ( $\geq 51$ tahun) dan penghasilan $<2.5$ ( $\leq$ Rp. 1.500.000,00), maka dari data diperoleh Tidak Macet sebanyak 11 nasabah dan Macet sebanyak 1 nasabah. Sehingga nasabah pada kelompok ini diduga akan mengalami kemacetan.

\section{Tingkat Akurasi Metode}

Pada tahap akurasi sistem perhitungan analisis Improved CHAID. Berikut tabel tingkat akurasi output Improved CHAID

Tabel 3.Tingkat Akurasi analisis Improved CHAID

\begin{tabular}{|c|c|}
\hline Output & Akurasi (\%) \\
\hline Improved CHAID & 90.5 \\
\hline
\end{tabular}

Tabel 3 menunjukkan hasil tingkat akurasi analisis Improved CHAID sebesar $90.5 \%$. Hal ini berarti metode ini sudah cukup baik, bila digunakan dalam pengklasifikasian calon nasabah peminjam kredit.

\section{Kesimpulan.}

BMT El Bummi 372 sebaiknya memprioritaskan calon nasabah dengan karakteristik nasabah menurut metode Improved CHAID yaitu nasabah dengan pendidikan (Diploma/S1/Profesi, S2/S3), usia $\leq 50$ tahun, ukuran keluarga $\leq 3$ orang dan penghasilan $>$ Rp. 1.500.000,00, maka diduga tidak akan mengalami kemacetan. Selain itu BMT sebaiknya memperhatikan (selektif) terhadap calon nasabah dengan karakteristik peminjamnya

\section{Pustaka}

Belaid, A. 2001. Data Mining in Document Structure Retroconversion. ACM Transactions on Computational Logic, Vol. 2, No. 3.

Kass, G., 1980, An Exploratory Technique for Investigating Large Quantities of Categorical Data, Applied Statistics, Vol. 29, No. 2, 119-127.

Kunto, Y.S. dan Hasana, S.N. 2006. Analisis CHAID sebagai Alat Bantu Statistika untuk Segmentasi Pasar. Jurnal Manajemen, Vol.1 No.2. Universitas Kristen Petra, Surabaya.

http://fportfolio.petra.ac.id/user_file s/05-011/MAR06010205.pdf.

Tanggal akses 13 September 2015.

Ramdhany, D.N., Kustiyo, A., Handharyani, E., dan Buono, A., 2006, Diagnosis Gangguan Sistem

Metode Improved CHAID (chi-squared automatic interaction detection) Pada Analisis Kredit Macet BMT (Baitul Mal wa Tamwil)

Muhammad Muhajir 
Urinari pada Anjing dan Kucing Menggunakan VFI 5, Institut Pertanian Bogor.

Samti,A.M, 2011. Faktor-faktor yang Mempengaruhi Pengembal Kredit Bermasalaholeh Debitur Gerai Kredit Verena Bogor. Skripsi S1, FEM IPB, Bogor.

Sharp, A., Romaniuk, J., and, Cierpicki, S., 2002, The Performance Of Segmentation Variables : A Comparative Study, http://anzmac.info/conference/199
8/Cd_rom/Sharp222.pdf, Tanggal akses : 15 September 2015.

Suhendi, H., Praja J.S., Abdullah H.N., Sadrah, H., Ridwan A.H., Solehudin, E., Janwari, Y., Yusuf, D.K., 2004, BMT dan Bank Islam, Bandung : Pustaka Bani Quraisy.

Metode Improved CHAID (chi-squared automatic interaction detection) Pada Analisis Kredit Macet BMT (Baitul Mal wa Tamwil) 